\title{
Przestrzenne badanie systemu porowego skał węglanowych na podstawie cyfrowej analizy obrazów mikrotomograficznych z wykorzystaniem języka Python
}

\author{
Adam Fheed ${ }^{1}$, Piotr Hadro'
}

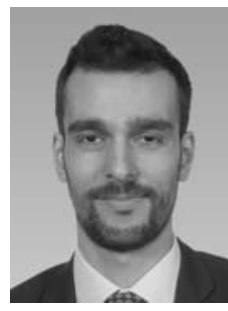

A. Fheed

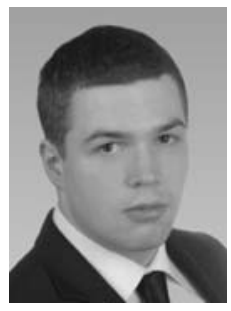

P. Hadro

Spatial analysis of carbonate pore system based on digital image analysis of $\mathrm{X}$-ray microtomography data using Python language. Prz. Geol., 69: 357-360; doi: 10.7306/2021.17

A bs tract. The main aim of this contribution is to combine a Python-supported analysis of X-ray microtomography $(\mu C T)$ images and the transmitted-light microscopy to resolve the factors controlling the variability of petrophysical parameters in carbonate rocks. A self-developed Python script for the evaluation of pore connectivity and the computation of pore sizes based on $\mu C T$ data was prepared. The script was launched on a carbonate sample withdrawn from a drill core representing the Late Permian Zechstein Limestone (Ca1) formation from the Wolsztyn Ridge area in West Poland. The sample was taken from the upper part of the isolated Kokorzyn Reef, corresponding to a brachiopod and bivalve-rich zone. The plug had a cylindrical shape, the diameter of $2.54 \mathrm{~cm}$ and the height of approximately $4.6 \mathrm{~cm}$. The entire volume of the plug was scanned using a GE Nanotom $S$ device. The 3D-reconstructed dataset obtained with spatial resolution of 0.02 mm underwent cropping, contrast adjustment, noise reduction and porosity extraction using open-source Fiji software. The binarized porosity image was loaded into the Python script. Python scripting was found efficient in carbonate pore system examination. The code first extracted the connected pore system of the largest volume and computed the smallest distances between porosity voxels and corresponding pore walls. The obtained results were confronted with the spatially-adjusted microphotographs taken in plane-polarized transmitted light. The results have shown that narrow and isolated pores occurred within the spines of brachiopods. The largest voids were found inside the brachiopod shells. Moreover, many pores were associated with partially dissolved fragments of bivalves. Porosity reduction was most outlined in the zones showing the scarcity of fossils.

Keywords: X-ray microtomography, Python, carbonate reservoir rocks, porosity

Skały węglanowe od lat budzą zainteresowanie naukowców ze względu na ich rolę w akumulacji węglowodorów (np. Esrafili-Dizaji, Rahimpour-Bonab, 2019). Ponadto są one ostatnio przedmiotem badań ukierunkowanych na podziemne magazynowanie gazu (Walsh i in., 2018) czy sekwestrację dwutlenku węgla (Raziperchikolaee i in., 2021). W konsekwencji zrozumienie wykształcenia skomplikowanej struktury porowej skał węglanowych oraz czynników ją warunkujących wydaje się bardzo istotne.

Jedną z powszechnie uznanych metod, skutecznych w analizie petrofizycznej konwencjonalnych, węglanowych skał zbiornikowych, jest rentgenowska mikrotomografia komputerowa ( $\mu \mathrm{CT}$; np. Arns i in., 2005; Zalewska i in., 2009; Strzelecki i in., 2020). Od lat 90. ubiegłego stulecia trwa intensywny rozwój metod analizy porowatości skał na podstawie $\mu$ CT (Keller, 1998; Van Geet i in., 2003; Arns i in., 2005; Dohnalik, Jarzyna, 2015). Za pośrednictwem tej metody uzyskuje się trójwymiarowe obrazy, na których są uwidocznione elementy skały o różnych współczynnikach absorpcji promieniowania rentgenowskiego (np. Zalewska i in., 2009). Otrzymane dane przetwarza się za pomocą techniki cyfrowej analizy obrazu (por. Leśniak, 1999). Cyfrowa analiza obrazu umożliwia rozdzielenie porów, tj. obszarów o niskiej absorpcji, od matrycy skalnej i ziaren charakteryzujących się wyższą absorpcją (por. Krakowska, Madejski, 2019). Istnieją liczne programy do analizy obrazu, jednak ich wykorzystanie często wiąże się z wykupieniem odpowiedniej licencji. Niektóre licencje nie zapewniają dostępu do bardziej zaawansowanych funkcji.
Dobrym wyjściem z tej sytuacji jest tworzenie własnych rozwiązań, korzystając np. ze środowiska Python. Skrypty języka Python umożliwiają wykonanie szybkiej analizy wielkości, geometrii i rozkładu porów w przestrzeni.

W niniejszym artykule opisano zastosowanie zestawu skryptów w języku Python do trójwymiarowej analizy stopnia połączenia porów i ich wielkości w wybranej próbce skały węglanowej. Głównym celem badań było ustalenie czynników, które uwarunkowały obserwowany w próbce rozkład porów. Zadanie to wykonano, bazując na analizie obrazów mikrotomograficznych i zdjęć mikroskopowych.

\section{MATERIAŁ I METODY}

Przeprowadzono badania mikrotomograficzne próbki wapienia cechsztyńskiego (Ca1), pobranej z głębokości 2251,2 m p.p.t., ze stropowej części izolowanej rafy Kokorzyna, zdeponowanej na wale wolsztyńskim. Próbka miała kształt walca o średnicy 2,54 cm i wysokości ok. 4,60 cm. Całą objętość próbki poddano skanowaniu tomografem GE Nanotom $S$ z detektorem Hamamatsu. Wykonano 1800 projekcji, a każdą z nich uśredniono pięciokrotnie. Otrzymany obraz składał się z 2302 warstw i miał rozdzielczość $0,02 \mathrm{~mm}$, co odpowiada wymiarom pojedynczego woksela.

Korzystając z oprogramowania Fiji, usunięto skrajne części obrazu, obarczone zakłóceniami, i poprawiono jego kontrast. Pracowano na obrazie 8-bitowym, przyciętym do prostopadłościanu o wymiarach 14,9 × 14,7 × 41,56 mm. Szum usunięto, używając rozszerzenia $\mathrm{BaSiC}$. Następnie

\footnotetext{
${ }^{1}$ AGH, Akademia Górniczo-Hutnicza im. Stanisława Staszica w Krakowie, Wydział Geologii, Geofizyki i Ochrony Środowiska, al. Mickiewicza 30,30-059 Kraków; fheed@agh.edu.pl; hadro@agh.edu.pl
} 
wyodrębniono z obrazu pory. Część obrazu zajętą przez pory poddano binaryzacji. Uzyskany obraz binarny porowatości poddano trójwymiarowej filtracji medianowej. Korzystając z tak przygotowanego obrazu, wybrano cztery obszary próbki charakteryzujące się zróżnicowanym zagęszczeniem i rozmiarami porów. $Z$ wybranych obszarów pobrano materiał na płytki cienkie do badań mikroskopowych. Próbki te zostały nasycone żywicą z dodatkiem niebieskiego barwnika. Płytki cienkie polerowane przeanalizowano pod mikroskopem polaryzacyjnym. Badania prowadzono w świetle przechodzącym.

Otrzymany wcześniej obraz binarny wczytano jako plik wejściowy do obliczeń w języku Python. Do obliczeń użyto bibliotek numpy, scipy oraz scikit-image. Otrzymane wyniki zwizualizowano dzięki bibliotece matplotlib i narzędziu mayavi. Skrypt zidentyfikował system porów połączonych o największej objętości, a także wskazał porowatość zamkniętą. Aby osiagnąć ten cel, przeprowadzono uprzednio zabieg etykietowania obiektów (labelling) na obrazie binarnym porowatości oraz użyto funkcji obliczającej objętość poszczególnych obiektów. Etykietowanie polegało na wyznaczeniu grup wokseli pozostających w bezpośrednim kontakcie. Na określony system porowy składały się jedynie połączone woksele. Następnie dla wszystkich wokseli reprezentujących porowatość pro- gram wyznaczył najmniejszą odległość do ścianek porów w przestrzeni euklidesowej. Odbyło się to za pośrednictwem funkcji distance_transform.edt modułu scipy.ndimage.morphology. W celu analizy zróżnicowania systemu porowego $\mathrm{w}$ przestrzeni program podzielił próbkę na 10 sektorów $(a-\mathrm{j})$, o wysokości 207 wokseli $(4,14 \mathrm{~mm})$ każdy. Dla każdego sektora obliczono maksymalną wartość odległości euklidesowej oraz lokalną porowatość próbki. Na trójwymiarowym modelu porowatości, aby poprawić jego czytelność, wyświetlono jedynie te pory, dla których otrzymana odległość euklidesowa była większa niż 5 wokseli $(0,1 \mathrm{~mm})$.

\section{WYNIKI BADAŃ}

Stwierdzono, że w analizowanej części próbki występuje 25050 systemów porowych. Największy połączony system ma objętość $1473,9 \mathrm{~mm}^{3}$. Stanowi on około $16 \%$ objętości badanej części próbki. Wybrany system porowy zawiera 90\% wszystkich porów występujących w próbce. Niektóre wyniki jego analizy przedstawiono na ryc. 1-2 oraz w tab. 1. Dzięki połączeniu badań mikroskopowych i cyfrowej analizy obrazów $\mu$ CT zauważono, że w analizowanej próbce skały występują dwie grupy porów. Grupę pierwszą stanowią pory związane bezpośrednio z bioklastami

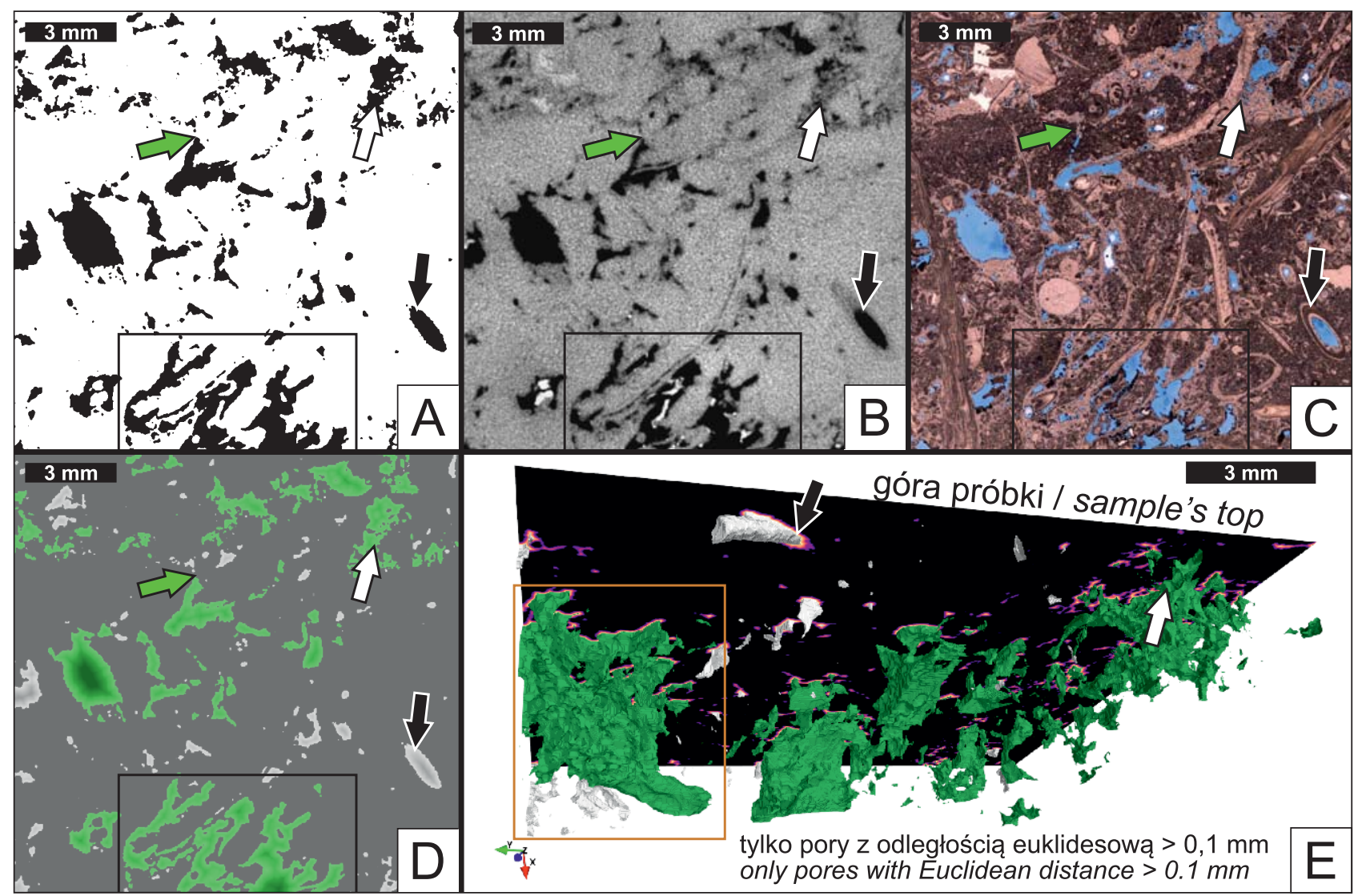

Ryc. 1. Porowatość próbki wapienia cechsztyńskiego (Ca1): A - obraz binarny; B - oryginalny obraz $\mu \mathrm{CT}$; $\mathbf{C}$ - rekonstrukcja obrazu całej płytki cienkiej z najwyżej położonej warstwy próbki przy 1N; D i E - obrazy binarne ilustrujące pory zamknięte (odcienie szarości) i otwarte (odcienie zieleni) - im ciemniejszy kolor na ryc. D, tym większa odległość od ścianek porów; białe strzałki - pory międzykrystaliczne; czarne strzałki - izolowane wnętrze kolca ramienionoga; zielone strzałki - mikroszczeliny; prostokąt - pory w muszlach małży i między nimi

Fig. 1. Porosity of the Zechstein Limestone (Ca1) sample: A - binarized image; $\mathbf{B}$ - original $\mu \mathrm{CT}$ image; $\mathbf{C}$ - thin section view reconstructed through merging of multiple microphotographs taken in plane-polarized light from the uppermost slice of the plug; $\mathbf{D}$ and $\mathbf{E}-$ binary images illustrating isolated (shades of grey) and communicated (shades of green) pores - the darker the colour in Fig. D, the larger the distance from pore walls; white arrows - intercrystal porosity; black arrows - isolated porosity in a brachiopod spine; green arrows - microfractures, channels; rectangle - pores accommodated within and between the bivalve shells 
lub naśladujące ich kształt po rozpuszczeniu (ryc. 1; kol. III na ryc. 2). W grupie drugiej można natomiast wyróżnić mikroszczeliny lub kanały (ryc. 1C), pory międzyziarnowe (kol. III na ryc. 2) i pory międzykrystaliczne (ryc. 1A-C; kol. I na ryc. 2).

Największą pojemnością charakteryzują się pory wewnątrz muszli ramienionogów (ryc. 2). Są one istotne w aspekcie gromadzenia płynów złożowych. Ich obecność zaznacza się dużymi maksymalnymi wartościami odległości euklidesowych oraz lokalnymi wzrostami porowatości (np. sektory a, b, f w tab. 1). Za sprawą występowania tego typu porów porowatość próbki przekracza w niektórych sektorach nawet $20 \%$ (por. tab. 1 i ryc. 2). Porom w muszlach ramienionogów towarzyszą inne pustki z pierwszej grupy, tj. pory w muszlach małży (ryc. 1C; kol. III na ryc. 2), rozpuszczone muszle małży, pustki znajdujące się w kolcach ramienionogów (ryc. 1D-E; kol. IV na ryc. 2) i pojedyncze pory stanowiące kanały osiowe liliowców (kol. III na ryc. 2).

Wyniki uzyskane dzięki użyciu skryptów języka Python pozwoliły zauważyć, że w dolnej partii próbki przeważają drobne, często zamknięte, pory z drugiej grupy (kol. II, IV na ryc. 2). Porowatość w tym obszarze próbki jest przeważnie mniejsza niż w jej górnej partii (tab. 1). Mniejsze maksymalne odległości euklidesowe w sektorach $g$ oraz $h$ sugerują występowanie porów o mniejszych rozmiarach (por. tab. $1 \mathrm{i}$ kol. IV na ryc. 2). W tym przypadku słabo wykształcona porowatość wynika z ograniczonej ilości bioklastów, które mogły być rozpuszczone (ryc. 2).

Dużą rolę w poprawie komunikacji między porami odgrywają rozpuszczone muszle małży (ryc. 1C, kol. III na ryc. 2). W miejscu dawnego występowania większych muszli tych organizmów porowatość zbliża się do 20\% (np. sektor $f$, tab. 1). Z kolei pory występujące w kolcach ramienionogów rzadko zapewniają ciąłe połączenie $\mathrm{z}$ innymi obiektami (ryc. 2). Razem z pozostałymi porami zamkniętymi stanowią one tylko nieco ponad $1 \%$ objętości analizowanej próbki (tab. 1).

\section{DYSKUSJA I WNIOSKI}

Wyłącznie ilościowe podejście do zagadnienia porowatości i przepuszczalności skał nie zawsze umożliwia zrozumienie dystrybucji porów w skale zbiornikowej. Gdy ośrodek jest mocno heterogeniczny, wskazana jest wnikliwa ocena wizualna danych przestrzennych, np. $\mu \mathrm{CT}$. Dzię-

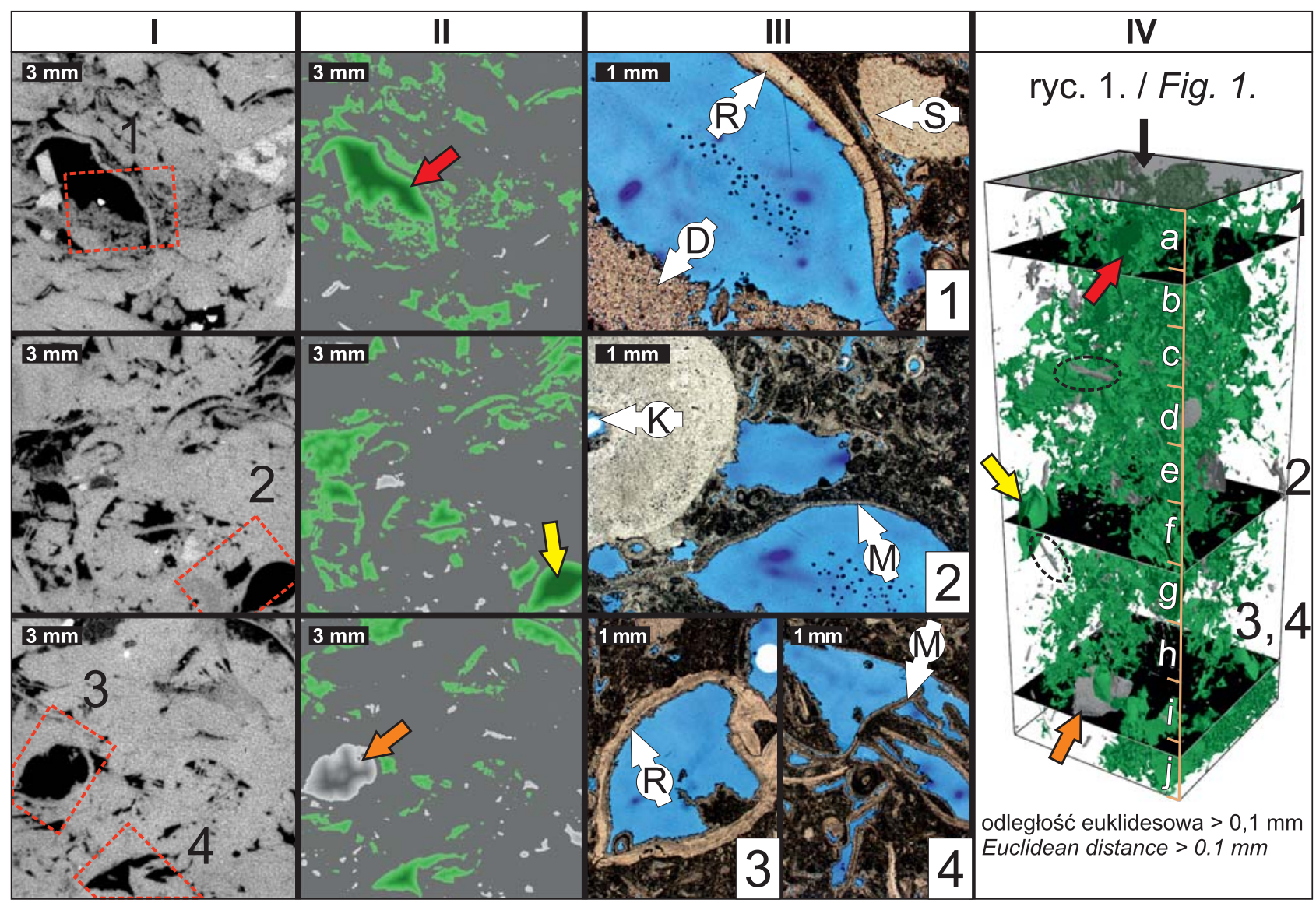

Ryc. 2. Zdjęcia mikroskopowe i obrazy binarne porowatości próbki wapienia cechsztyńskiego (Ca1) - ich lokalizację pokazano w kol. IV. Kolumna I: obrazy $\mu \mathrm{CT}$ z czerwonymi liniami wskazującymi zasięg ponumerowanych zdjęć mikroskopowych w świetle przechodzącym (1N; kol. III). Kolumna II: przekroje przez model porów z kol. IV (kolory jak na ryc. 1). Kolorowe strzałki wskazują lokalizacje porów na modelu, gdzie przerywaną linią zaznaczono pory zamknięte w kolcach ramienionogów. Sektory próbki, z których generowano dane ilościowe, pokazano w kol. IV; $\mathbf{R}$ - muszla ramienionoga; $\mathbf{S}$ - fragment szkarłupnia; $\mathbf{D}$ - kryształy dolomitu i pory międzykrystaliczne; $\mathbf{K}$ - izolowany kanał osiowy liliowca; $\mathbf{M}$ - muszla małża

Fig. 2. Microphotographs and binarized porosity images with spatial location indicated in col. IV. Col. I: $\mu \mathrm{CT}$ images with red lines showing the outreach of the numbered, plane-polarized light microphotographs from col. III. Col. II: cross-sections through the 3D model of pores presented in col. IV (colour coding as in Fig. 1). The coloured arrows show chosen pores on the spatial model, where dashed lines indicate isolated pores within the brachiopod spines. Sample sectors from which quantitative data were generated are shown in col. IV; $\mathbf{R}$ - brachiopod shell; $\mathbf{S}$ - echinoderm fragment; $\mathbf{D}$ - dolomite crystals with intercrystal pores; $\mathbf{K}$ - isolated crinoid axial canal; $\mathbf{M}$ - bivalve shell 
Tab. 1. Podstawowe parametry opisujące przestrzeń porową analizowanej próbki. Lokalizację sektorów pokazano na ryc. 2 Tab. 1. Basic parameters describing the pore system of the analyzed sample. Locations of particular sectors are indicated graphically in Fig. 2

\begin{tabular}{|c|c|c|}
\hline $\begin{array}{c}\text { Sektor } \\
\text { próbki } \\
\text { Sample } \\
\text { sector }\end{array}$ & $\begin{array}{c}\text { Odleglość euklidesowa } \\
- \text { maksimum [woksele] } \\
\text { Euclidean distance } \\
- \text { maximum value [voxels] }\end{array}$ & $\begin{array}{c}\text { Porowatość } \\
\text { w sektorze } \\
\text { Local porosity } \\
\text { [\%] }\end{array}$ \\
\hline $\mathrm{a}$ & 50 & 16 \\
\hline $\mathrm{b}$ & 58 & 21 \\
\hline $\mathrm{c}$ & 28 & 21 \\
\hline $\mathrm{d}$ & 47 & 23 \\
\hline $\mathrm{e}$ & 37 & 18 \\
\hline $\mathrm{f}$ & 54 & 19 \\
\hline $\mathrm{g}$ & 38 & 16 \\
\hline $\mathrm{h}$ & 31 & 13 \\
\hline $\mathrm{i}$ & 56 & 10 \\
\hline $\mathrm{j}$ & 52 & 25 \\
\hline \multicolumn{2}{|c|}{ Cala próbka / Whole sample } \\
\hline \multicolumn{2}{|c|}{ Porowatość zamknięta / Isolated porosity [\%] } \\
\hline Porowatość otwarta / Effective porosity [\%] & 1,75 \\
\hline \multicolumn{2}{|c|}{ Porowatość całkowita / Total porosity [\%] } & 16,19 \\
\hline
\end{tabular}

ki wykorzystaniu skryptów języka Python, użytkownik zyskuje możliwość automatyzacji tego procesu. Ponadto środowisko Python gwarantuje dostęp do licznych narzędzi wizualizacji otrzymanych wyników, przez co ułatwia ich interpretację (Gouillart i in., 2016).

Za pomocą skryptów języka Python, opracowanych przez autorów niniejszego artykułu, udało się wskazać obszary próbki o zróżnicowanych parametrach petrofizycznych i określić zależności między typami porów a stopniem ich skomunikowania. Istotnym elementem badań było zestawienie zdjęć mikroskopowych z obrazami $\mu \mathrm{CT}$. Zdjęcia mikroskopowe ułatwiają identyfikację bioklastów i składu mineralnego, podczas gdy dane $\mu \mathrm{CT}$ umożliwiają analizę rozkładu przestrzeni porowej w próbce. Łącząc wymienione techniki badań, możliwe jest ustalenie czynników odpowiedzialnych za wytworzenie określonej morfologii porów w skale. W przypadku badanej próbki skały węglanowej stwierdzono, że system porowy jest uzależniony od porowatości pierwotnej, zachowanej w muszlach ramienionogów. System ten jest wsparty licznymi, częściowo rozpuszczonymi muszlami małży, które na ogół mają niższy potencjał fosylizacyjny (por. Scholle, Ulmer-Scholle, 2003). Wyniki badań wskazały, że pory są najlepiej połączone w obszarach próbki o dużym zagęszczaniu bioklastów, takich jak np. muszle ramienionogów. Pory znajdujące się w muszlach mogły zostać połączone ze sobą na drodze rozpuszczania sąsiadujących z nimi części skały. Zaobserwowano również, że naturalne pustki występujące w kolcach ramienionogów najczęściej są porami zamkniętymi. Może to wynikać z ich fragmentacji i transportu. W konsekwencji zdolność takich struktur do przewodzenia płynów złożowych jest bardzo mała. Dodatkowo w analizowanej próbce stwierdzono występowanie porów międzykrystalicznych, reprezentujących mikroporowatość. Ich obecność należy wiązać m.in. z procesem dolomityzacji skał.
Analiza węglanowych skał zbiornikowych jest bardzo wymagająca z uwagi na ich biogeniczne pochodzenie i dużą podatność na diagenezę (np. Drabik i in., 2018). Jak wykazano w niniejszym artykule, połączenie analizy obrazów $\mu \mathrm{CT}$ w środowisku Python i badań mikroskopowych znacząco ułatwia wskazanie czynników odpowiedzialnych za lokalne zmiany właściwości zbiornikowych skał węglanowych. Wiedza na temat tych czynników może być wykorzystana do rozpoznania rozkładu porów w poziomie zbiornikowym i jego lepszego zagospodarowania przemysłowego.

Autorzy serdecznie dziękują Pawłowi Raczyńskiemu z Uniwersytetu Wrocławskiego za pomoc w identyfikacji skamieniałości. Podziękowania za cenne wskazówki kierujemy także do recenzentów pracy: dr hab. Katarzyny Jarmołowicz-Szulc, prof. PIG-PIB oraz dr. inż. Grzegorza Leśniaka. Badania wykonano w ramach grantu Preludium NCN UMO-2016/23/N/ST10/00350. Artykuł otrzymał wsparcie finansowe Akademii Górniczo-Hutniczej w Krakowie (Wydział Geologii, Geofizyki i Ochrony Środowiska, Katedra Surowców Energetycznych). Dofinansowanie pochodziło ze środków funduszu statutowego nr 16.16.140.315/05.

\section{LITERATURA}

ARNS C.H., BAUGET F., LIMAYE A., SAKELLARIOU A., SENDEN T.J., SHEPPARD A.P., SOK R.M., PINCZEWSKI W.V., BAKKE S., BERGE L.I., ØREN P.-E., KNACKSTEDT M.A. 2005 - Pore-scale characterization of carbonates using X-Ray microtomography. SPE J., 10: 475-484. DOHNALIK M., JARZYNA J. 2015 - Determination of reservoir properties through the use of computed X-ray microtomography - eolian sandstone examples. Geol. Geophys. Environ., 41: 223-248.

DRABIK K., URBANIEC A., MIKOŁAJEWSKI Z., DOHNALIK M. 2018 - Przykłady zastosowania metody rentgenowskiej tomografii komputerowej (CT) rdzeni wiertniczych w analizie skał węglanowych. Wiad. Naftowe i Gazownicze, 21: 4-10.

ESRAFILI-DIZAJI B., RAHIMPOUR-BONAB H. 2019 - Carbonate reservoir rocks at giant oil and gas fields in SW Iran and the adjacent offshore: a review of stratigraphic occurrence and poro-perm characteristics. J. Pet. Geol., 42: 343-370.

GOUILLART E., NUNEZ-IGLESIAS J., VAN DER WALT S. 2016 Analyzing microtomography data with Python and the scikit image library. Adv. Struct. Chem. Imag., 2: 18.

KELLER A. 1998 - High resolution, non-destructive measurement and characterization of fracture apertures. Int. J. Rock Mech. Min. Sci., 35: 1037-1050.

KRAKOWSKA P., MADEJSKI P. 2019 - Research on fluid flow and permeability in low porous rock sample using laboratory and computational techniques. Energies, 12: 4684.

LEŚNIAK G. 1999 - Zastosowanie komputerowej analizy obrazu w badaniach petroflzycznych. Prz. Geol., 47: 644-651.

RAZIPERCHIKOLAEE S., COTTER Z., GUPTA N. 2021 - Assessing mechanical response of $\mathrm{CO}_{2}$ storage into a depleted carbonate reef using a site-scale geomechanical model calibrated with field tests and InSAR monitoring data. J. Nat. Gas. Sci. Eng., 86: 103744.

SCHOLLE P.A., ULMER-SCHOLLE D.S. 2003 - A color guide to the petrography of carbonate rocks: grains, textures, porosity, diagenesis. AAPG Memoir, 77, Tulsa.

STRZELECKI P.J., FHEED A., RACZYŃSKI P. 2020 - 3D geometric evaluation of porosity types in carbonates. AIP Conf. Proc., 2209: 030002-1-030002-7.

VAN GEET M., LAGROU D., SWENNEN R. 2003 - Porosity measurements of sedimentary rocks by means of microfocus X-ray computed tomography $(\mu \mathrm{CT})$. [W:] MEES F., SWENNEN R., VAN GEET M., JACOBS P. (red.), Applications of X-ray computed tomography in the Geosciences. Geol. Soc. Spec. Pub., 215, Londyn: 51-60.

WALSH R., OTHMAN N., CALDER N., STERLING S., AVIS J. 2018 Combining TOUGH2 and FLAC3D to solve problems in underground gas storage. Transp. Porous Med., 123: 501-519.

ZALEWSKA J., DOHNALIK M., SIKORA G. 2009 - Możliwości rentgenowskiej tomografii komputerowej w rozpoznawaniu, obrazowaniu i szacowaniu wielkości szczelin. Nafta-Gaz, 65: 296-303.

Praca wpłynęła do redakcji 31.03.2021 r.

Akceptowano do druku 27.04.2021 r. 